\title{
Use of transthoracic cryoanalgesia during the Nuss procedure
}

\author{
Sunghoon Kim, MD, ${ }^{\mathrm{a}}$ Olajire Idowu, MD, ${ }^{\mathrm{a}}$ Barnard Palmer, MD, ${ }^{\mathrm{b}}$ and Sang H. Lee, $\mathrm{MD},{ }^{\mathrm{c}}$ Oakland and \\ San Jose, Calif
}

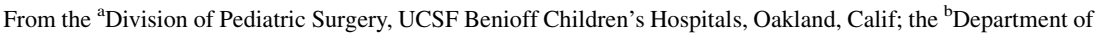
Surgery, University of California, San Francisco-East Bay, Oakland, Calif; and the ${ }^{\mathrm{c}}$ Department of Cardiothoracic Surgery, Regional Medical Center, San Jose, Calif.

Disclosures: Authors have nothing to disclose with regard to commercial support.

Received for publication Aug 15, 2015; revisions received Sept 17, 2015; accepted for publication Sept 27, 2015.

Address for reprints: Sang H. Lee, MD, Department of Cardiothoracic Surgery, Regional Medical Center,

455 O’Connor Dr, Suite 280, San Jose, CA 95128 (E-mail: sangleemd@ hotmail.com).

J Thorac Cardiovasc Surg 2016;151:887-8

$0022-5223 / \$ 36.00$

Copyright (c) 2016 by The American Association for Thoracic Surgery

http://dx.doi.org/10.1016/j.jtcvs.2015.09.110
}

The Nuss procedure has become the preferred method for pectus excavatum repair. It is, however, a surgical procedure that causes significant postoperative pain and long-term pain during the recovery phase. Thoracic epidural analgesia and patient-controlled analgesia are frequently used methods for postoperative pain relief after the procedure. ${ }^{1}$ Cryoanalgesia, which was introduced in 1970s, is an alternate pain relief method that is used for thoracotomy operations. ${ }^{2}$ One advantage of cryoanalgesia relative to conventional pain relief methods is that its analgesic effect lasts for several weeks. This long-term efficacy is appropriate for the Nuss procedure, which produces postoperative pain for weeks. Although there are reports that show cryoanalgesia is superior to patient-controlled analgesia for postthoracotomy pain management in the immediate postoperative period, cryoanalgesia for thoracoscopic procedures has not been well described in the literature. ${ }^{3}$ In particular, when a patient lies supine, as in the Nuss procedure, the application of a thoracoscopic cryoprobe on the posterolateral intercostal nerves is difficult because of the curvature of the ribs. We describe a thoracoscopic transthoracic cryoanalgesia technique applied during the Nuss procedure that overcomes this access difficulty. This method facilitates a cryoprobe application without the

\section{TECHNIQUE}

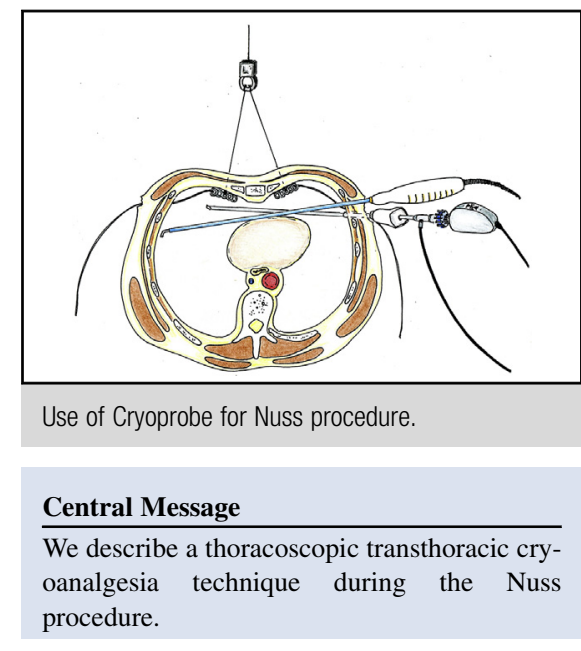

See Editorial Commentary page 889.

need for additional thoracoscopic ports and improves operative field of view.

To obtain a direct view of the posterolateral intercostal nerves of a patient with pectus excavatum, a rigid thoracoscope is placed into the chest contralateral to the chest side that is to be examined. The patient's anterior mediastinum is dissected to allow passage of the scope and a cryoprobe (cryoICE; AtriCure, West Chester, Ohio) across the mediastinum. Before the passage of the instruments across the anterior mediastinum, the anterior chest wall is elevated with a T-fastener suture technique, which has been previously described. ${ }^{4}$
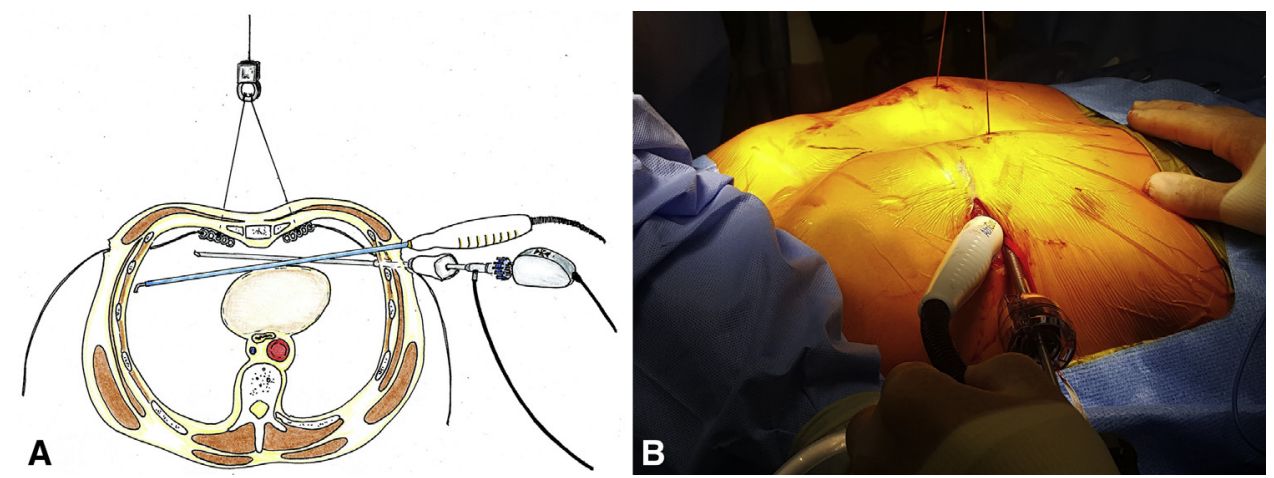

FIGURE 1. A, A thoracoscope and a cryoprobe traverse across the anterior mediastinum, which has been dissected. The anterior chest has been elevated with sutures tied to metal plates placed within the thorax. B, An external view of the scope and the cryoprobe is shown. 


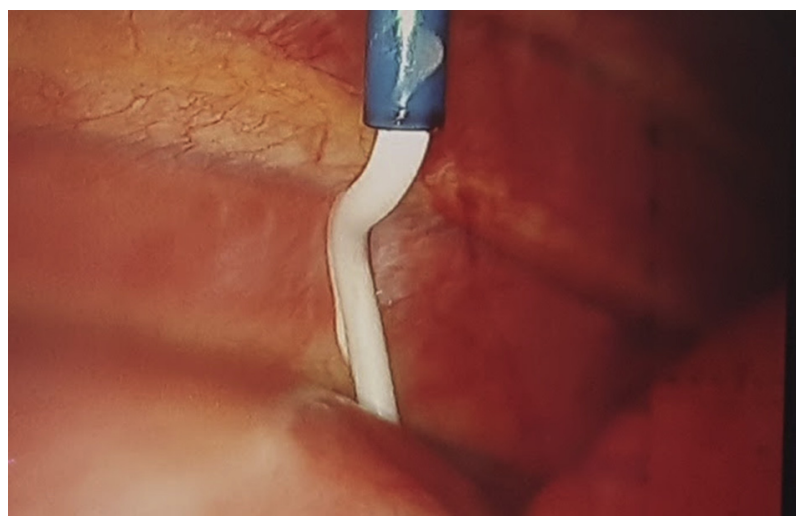

FIGURE 2. The cryoprobe tip is placed perpendicular to an intercostal nerve. The nerve is treated at $-60^{\circ} \mathrm{C}$ for 2 minutes.

The patient was an 18-year-old man with a severe asymmetric pectus excavatum with a Haller index of 3.9. After general anesthesia and endotracheal tube intubation, the patient lay supine on the operating table on a thick blanket which ran along the length of the back to the buttock. Bupivacaine $0.5 \%$ was injected into the lateral chest wall, where bilateral transverse incisions were later made. The incisions made on the chest wall were to be used later for the insertion of a metal bar and stabilizers. Through the incision on the left chest wall, a 5-mm port was inserted, and carbon dioxide at $5 \mathrm{~mm} \mathrm{Hg}$ pressure was insufflated to depress the lung to create space. A $30^{\circ}$ thoracoscope was used to view the internal thorax. The anterior chest wall was elevated with the T-fastener suture technique and a Rultract Skyhook System (Rultract, Cleveland, Ohio). With the chest elevated, through the left chest incision, an endoscopic Kittner dissector and a thoracoscope fitted with Vasoview transparent dissector tip (Maquet, Rastatt, Germany) were used to dissect the anterior mediastinum under direct camera view from the left side of the chest to the right.

Once the passage across the anterior mediastinum had been cleared, the thoracoscope was placed into the port, and the cryoprobe was bluntly inserted through the same chest wall incision and passed across the anterior mediastinum into the contralateral chest cavity (Figure 1).
The cryoprobe tip was then applied onto the intercostal nerve, lateral to the chest incision. About a 5-mm length of the intercostal nerve was treated by placing the probe perpendicular to the nerve at $-60^{\circ} \mathrm{C}$ continuously for 2 minutes (Figure 2). Afterward, the probe was allowed to thaw and to fall off the nerve without traction. Five intercostal nerves were treated: first at the level of the chest incision, then 2 levels above the incision and 2 levels below the incision. The contralateral chest was similarly treated. After the bilateral chest wall cryoanalgesia, the Nuss procedure was completed.

\section{DISCUSSION}

Research on optimal pain management for the Nuss procedure is ongoing. We presented in this report another analgesia technique that could be applied to the procedure. The advantage of cryoanalgesia relative to other pain-management techniques is that the pain relief is long lasting with a single application during the operation. The anterior chest analgesia is effective for about 1 month, which is equivalent to time needed for the intercostal nerve axonal regeneration. This is the typical duration needed by patients after the Nuss procedure to recover fully from their surgical pain.

The transthoracic approach described here should increase the ease of cryoprobe application during the Nuss procedure without the need for additional incisions or ports.

\section{References}

1. Weber T, Mätzl J, Rokitansky A, Klimscha W, Neumann K, Deusch E, Medical Research Society. Superior postoperative pain relief with thoracic epidural analgesia versus intravenous patient-controlled analgesia after minimally invasive pectus excavatum repair. J Thorac Cardiovasc Surg. 2007; 134:865-70.

2. Nelson KM, Vincent RG, Bourke RS, Smith DE, Blakeley WR, Kaplan RJ, et al. Intraoperative intercostal nerve freezing to prevent postthoracotomy pain. Ann Thorac Surg. 1974; 18:280-5.

3. Moorjani N, Zhao F, Tian Y, Liang C, Kaluba J, Maiwand MO. Effects of cryoanalgesia on post-thoracotomy pain and on the structure of intercostal nerves: a human prospective randomized trial and a histological study. Eur J Cardiothorac Surg. 2001;20:502-7.

4. Kim D, Idowu O, Palmer B, Kim S. Anterior chest wall elevation using a T-fastener suture technique during a Nuss procedure. Ann Thorac Surg. 2014; 98:734-6. 